\title{
Larvae of Rhizocephalans with a Kentrogonid Type of Development and their Significance in the Taxonomy and Phylogeny of Parasitic Crustaceans
}

\author{
O. M. Korn ${ }^{a, *}$ and D. D. Golubinskaya ${ }^{a}$ \\ ${ }^{a}$ Zhirmunsky National Scientific Center of Marine Biology, Far Eastern Branch, Russian Academy of Sciences, \\ Vladivostok, 690041 Russia \\ *e-mail: olgamkorn@mail.ru
}

Received November 23, 2020; revised January 27, 2021; accepted March 5, 2021

\begin{abstract}
This review is devoted to the pelagic larvae of rhizocephalan crustaceans with a kentrogonid type of development (Thecostraca: Cirripedia: Rhizocephala). These barnacles have undergone such a significant reduction of adult stages connected with the parasitic lifestyle that only the presence of a nauplius larva in their development indicates that this unique group belongs to crustaceans. The main attention is paid to the morphological characters of the larvae that can be used in the taxonomy and phylogeny of Rhizocephala. The differences between the larvae of peltogastrid and sacculinid types are discussed. The sexual dimorphism of cyprids associated with different functions of male and female larvae is analyzed.
\end{abstract}

Keywords: Rhizocephala, nauplius, cypris larva, sexual dimorphism

DOI: $10.1134 / \mathrm{S} 1063074021050072$

Rhizocephalan crustaceans (Thecostraca: Cirripedia: Rhizocephala) are parasites of other crustaceans, mainly decapods, less often peracarids, stomatopods, and barnacles. This is a unique superorder of parasitic barnacles that have undergone a significant reduction of adult stages and have lost almost all features of arthropods, including segmentation, appendages, and internal organs, except the gonads. Only the presence of the nauplius, a typical larva of crustaceans, in the development of rhizocephalans indicates their belonging to this group.

The biology and life cycles of Rhizocephala have been well studied and described in detail in a number of reviews [23, 24, 29-31, 63]. The adult female rhizocephalan is represented by the interna, a network of rootlets in the body of the host providing the parasite with trophic resources, and the externa, its reproductive body. The mantle cavity of the externa houses a visceral sac, which contains the developing ovary and receptacles with cryptic dwarf males, which are reduced to spermatogenic tissue. Thus, rhizocephalan crustaceans exhibit cryptogonochorism, an extreme form of sexual dimorphism, when the dwarf males undergo the reduction of all tissues, except the spermatogenic tissue.

Mature oocytes are released into the mantle cavity of the externa, where fertilization and development of embryos to the nauplius stage take place (Fig. 1). In most rhizocephalans, the larvae appear in the plank- ton at this stage and, after several naupliar molts, change into a cypris larva, which searches for a new host or juvenile externa. Naupliar stages are lost in true freshwater, semi-terrestrial, and deep-sea species, as well as in all species with an akentrogonid type of development that release cypris larvae into the external environment $[8,30]$.

Rhizocephalan larvae are heterosexual. In species with kentrogonid type of development, female cypris larvae settle on a new host and molt into a highly specialized stage, the kentrogon, which injects with a cuticular stylet through the integument the next stage, vermigon. The worm-like vermigon stage develops into the interna in the body of the host. The interna grows; after some time the externa is formed, which breaks through the integument and comes out. Male larvae settle on the mantle opening of the juvenile externa, metamorphose into the trichogon stage, which is similar to the vermigon. The trichogon enters the receptacles and implants the spermatogenic tissue in them $[12,13,15,20,21]$. In the akentrogonid type of development, the kentrogon, vermigon, and trichogon stages are absent, and the penetration of female larvae into the host and the entrance of male larvae into the juvenile externa occur via antennules of the cypris larva [22].

During the breeding season, the externa produces many generations of larvae. In addition, the parasite is capable of asexual reproduction with the formation of 


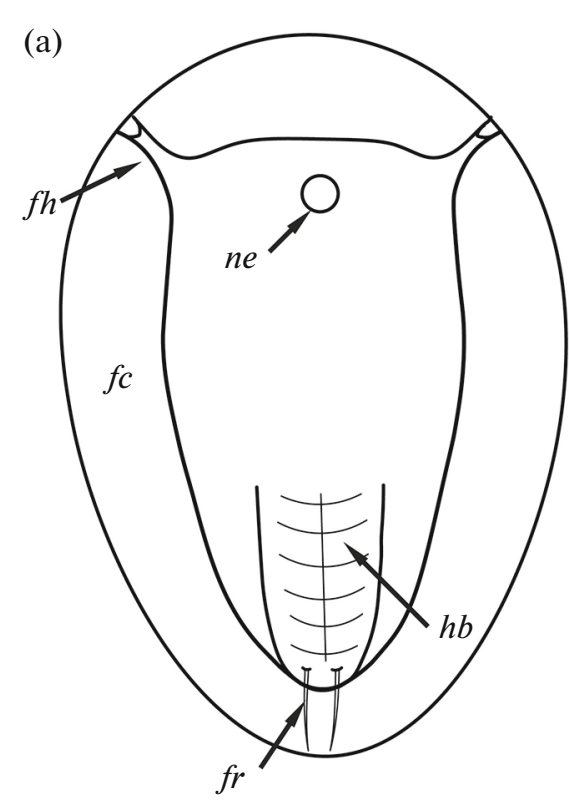

(b)

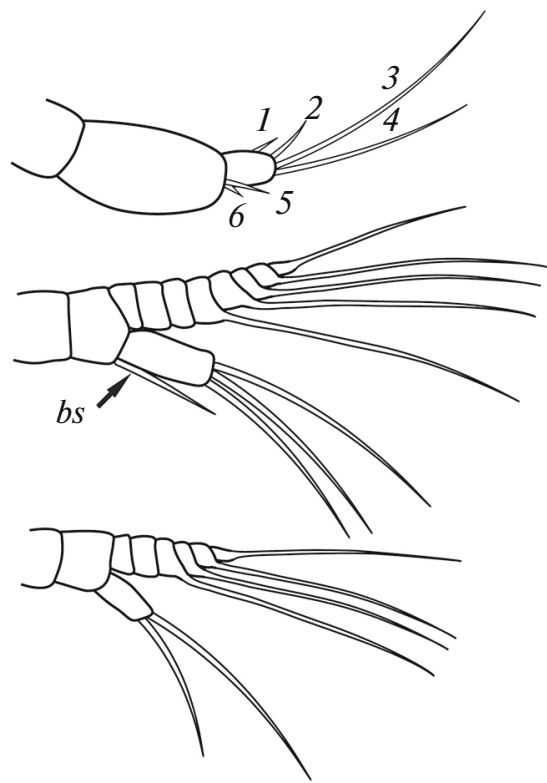

Fig. 1. The outlines of the nauplius of Rhizocephala: general appearance (a), antennule (b), antenna (c), and mandible (d). Designations: $b s$, a seta on the basis of the antenna; $f c$, flotation collar; $f h$, frontolateral horns; $f r$, furca; $h b$, hindbody; $n e$, naupliar eye; (1-6) antennular setae.

colonies, resulting in the appearance of multiple externae on the host body. Re-infestation with new larvae is also possible. The alternation of sexual and asexual reproduction leads to the appearance of a huge number of larvae in the plankton and, consequently, to the infestation of a significant part of the host population [38, 39].

The number of structural features of the externa, the visible part of the rhizocephalan crustacean, is limited; therefore, the study of rhizocephalan larvae is necessary for understanding the taxonomy and phylogeny of this unique group of parasites. Before the introduction of molecular taxonomy techniques, the affinity between groups of the class Thecostraca was exclusively confirmed by larval morphology data [23, $28,32,35]$. The presence of the cypris larva in the development cycle of all subclasses of Thecostraca confirms the monophily of this class. The presence of frontolateral horns in the nauplii of all three superorders of Cirripedia confirms the monophily of this subclass [25].

Well-developed planktotrophic larvae of free-living barnacles have been studied for many years using only light microscopy $[52,46]$, while reduced lecitotrophic rhizocephalan larvae have been observed using scanning electron microscopy almost from the very beginning of research in order to maximize the number of taxonomic characters. Currently, Rhizocephala includes 250-300 known species [26, 34]; however, the complete larval development has been studied in no more than 10 of them $[9,10,19,47,48$, $54,57-59,61,66]$. In a number of species, individual larval stages or individual larval structures have been studied or illustrated $[7,14,33,37,41,44,53,56,60$, $62,67-69]$.

\section{Taxonomy of Rhizocephala}

The class Thecostraca unites three subclasses of crustaceans: Cirripedia, Ascothoracida, and Facetotecta [51], which, in the course of adjustment to the conditions of existence (parasitism, sessile or boring lifestyle) acquired unique morphological adaptations and unusual life cycles [25].

The superorder of rhizocephalan crustaceans (Cirripedia: Rhizocephala) was traditionally divided into two orders: Kentrogonida, which have a kentrogon stage in their development and Akentrogonida, which lost this stage of the life cycle [24, 29, 30, 50, 51]. However, recent molecular data show that these taxa are paraphyletic [34]. At present, Kentrogonida and Akentrogonida can only be regarded as lifestyles or types of development of rhizocephalan crustaceans.

Genetic studies introduced other significant changes into the taxonomy of Rhizocephala [11, 16, 17, 36, 49]. The most important change is the uniting of the family Peltogastridae with the paraphyletic family Lernaeodiscidae and the retention of the monophyletic genus Lernaeodiscus [34]. Rhizocephalans of the family Lernaeodiscidae mostly parasitize crabs, while peltogastrids are parasitic on hermit crabs; therefore, the adult morphology of parasites from these families differs significantly. However, the nauplii and cyprids have many features in common, which allows one to consider them as peltogastrid-type larvae and confirms the correctness of uniting the fami- 
lies Peltogastridae and Lernaeodiscidae on the basis of molecular data. The genus Peltogasterella was separated from the family Peltogastridae into a family, the Peltogasterellidae, uniting peltogastrids with colonial externa, which may be their apomorphic trait [34]. However, the larvae of these two families have many features in common; therefore, the nauplii and cyprids of the Peltogasterellidae can also be assigned to the peltogastrid-type larvae.

Based on molecular analysis, species of the genus Sacculina from the paraphyletic family Sacculinidae were divided between two families, Sacculinidae and Polyascidae [34]. Three species of the genus Sacculina remained in the family Sacculinidae, along with the genera Heterosaccus, Loxothylacus, Ptychascus, and Sesarmaxenos. The family Polyascidae included the monophyletic genus Polyascus and five other species from the genus Sacculina forming a genus, Parasacculina. By default, 164 species remain in the family Sacculinidae, for which genetic data are not yet available. The adults and larvae of Sacculina and Parasacculina are similar in structure. Morphological evidence for the new system is to be analyzed. The larvae of the families Sacculinidae and Polyascidae, in contrast to the nauplii and cyprids of the families Peltogastridae and Peltogasterellidae, can be considered as sacculinid-type larvae.

\section{The Number of Naupliar Stages and Duration of Larval Development}

In rhizocephalans with the kentrogonid type of development, only four naupliar stages were initially described, one of which (the third or fourth) was probably missed $[10,19,61,64,65]$. This can be explained by the fact that larvae from culture were observed once a day (which is correct for nauplii of Thoracica), while the molting of rhizocephalan nauplii occurs more often, every 5-16 h under optimal conditions. Five naupliar stages were first recorded in Briarosaccus tenellus [66]. Later, the exact number of stages in some species was determined by counting larval exuviae at each molt. As a result, the genera Peltogasterella [4, 57], Peltogaster [2], Sacculina [5], Polyascus [6], and Heterosaccus [54] were found to have five naupliar stages. Careful monitoring and observation of larvae every $4 \mathrm{~h}$ showed that the pelagic period of the wellstudied species Sacculina carcini also includes five naupliar stages [58], but not four stages, as suggested previously $[10,61]$. However, only four naupliar stages were found in Parasacculina sinensis [9] and Polyascus planus [59], despite that the larvae of the latter species were observed every $6 \mathrm{~h}$.

The length of the period of larval development in the plankton differs among species and is probably determined by temperature. In warm-water species, the cypris larva appears on the third or fourth day [1, 2, 4-6, 9, 42, 43, 47, 48, 54, 57-59]. Cold-water species such as Briarosaccus callosus [19] and B. tenellus
[66] need about 1 month to develop. It cannot be ruled out that species whose larvae stay in the plankton for a long period of time and are poorly studied have a greater number of naupliar stages. As an example, the first stage of $B$. tenellus [66] morphologically corresponds to the second stage, so there are probably six naupliar stages in this species [57]. Recently, it was found that the cold-water facetotectan Hansenocaris itoi in the White Sea has seven naupliar stages [45], while only five naupliar stages were described for the warm-water $H$. furcifera [40]. It is possible that the number of naupliar stages in Rhizocephala varies from four to six, with a basic value of five [26].

\section{Lecithotrophy of Larvae}

Both nauplii and cypris larvae of Rhizocephala do not feed. Due to lecithotrophy, the structures associated with feeding are reduced in rhizocephalan nauplii [61]. The labrum is a small process in comparison with a fairly large upper lip of the basic planktotrophic larva of Cirripedia. The plumose setae on the appendages, which in planktotrophic nauplii form a filtering apparatus for catching phytoplankton, are reduced in rhizocephalan larvae. Gnathobases are completely absent. Flotation setae are also less developed, since the rhizocephalan larvae, as compared to the nauplii of free-living cirripedes, spend a short time in the plankton and are not transported over long distances.

\section{Flotation Collar (Fig. 2)}

The nauplii of some rhizocephalan species develop a unique structure, the flotation collar, enabling the larva to soar in the water column [33]. This structure was not found in larvae of other groups of crustaceans [26]. The flotation collar is found in nauplii of the genera Peltogaster, Briarosaccus, Septosaccus, Ommatogaster, Lernaeodiscus, Peltogasterella, Cyphosaccus, and Parthenopea. In members of the first two genera, the collar is large and clearly visible; its cuticle has a distinct reticulate pattern (Figs. 2a, 2e) [19, 29, $48,66]$. In other genera, except Parthenopea, the flotation collar is thin, inconspicuous, easily lost, and looks smooth and transparent in a light microscope. The reticulate pattern, which is observed in scanning electron photographs (Figs. 2b, 2f) may be largely due to the drying procedure $[33,47,57,69]$. The nauplii of a single genus Parthenopea in the family Parthenopeidae exhibit a third type of flotation collar (Figs. 2c, 2g) that has a characteristic porous structure. In addition, the flotation collar of Parthenopea has a caudal process, which is not found in any of the studied rhizocephalan species (Fig. 2c) [7]. The larvae of Sacculina, Parasacculina, Heterosaccus, and Polyascus lack the flotation collar (Fig. 2d).

As a rule, the flotation collar appears in the second stage, but a narrow transparent rim around the body of the first naupliar stage is indicative of the fact that the 
(a)

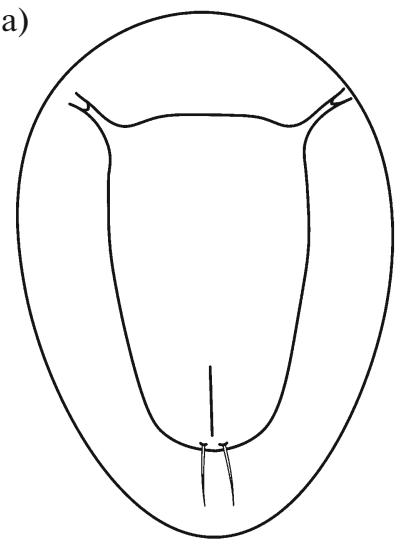

(b)

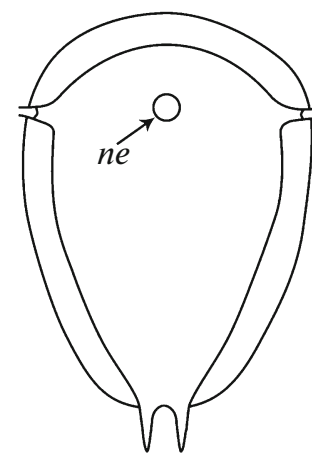

(c)

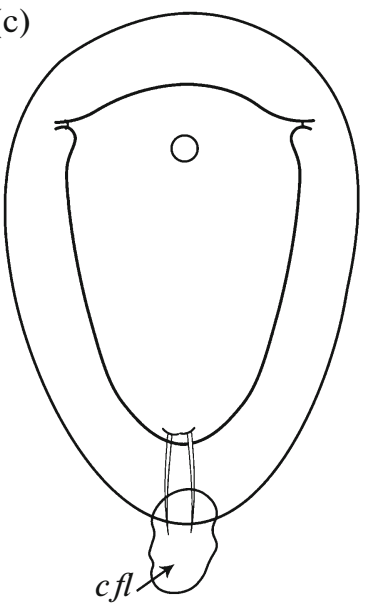

(d)

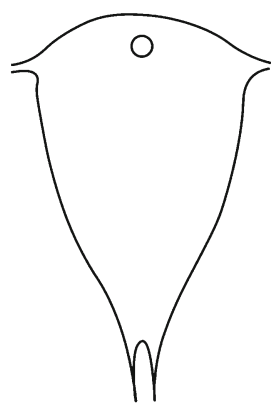

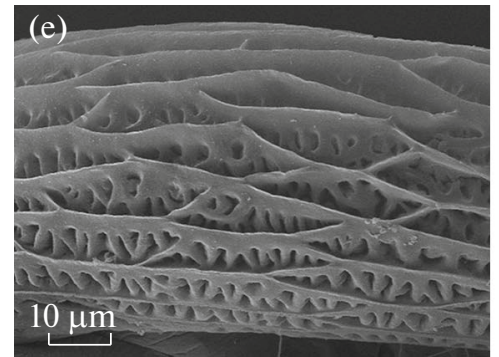
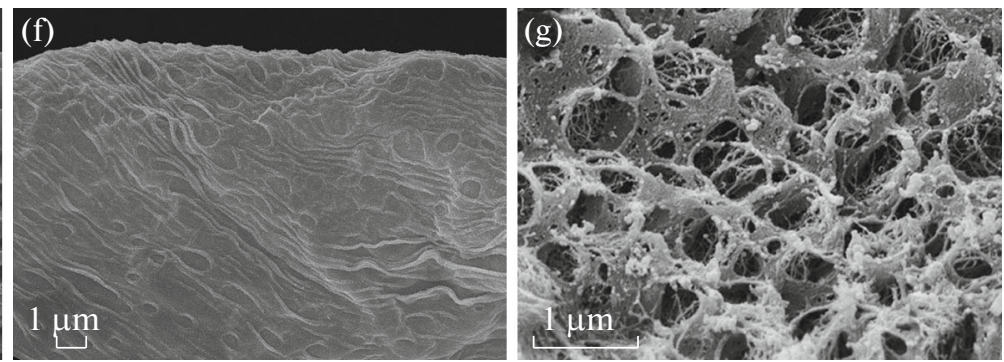

Fig. 2. The external appearance $(\mathrm{a}-\mathrm{d})$ and structure $(\mathrm{e}-\mathrm{g})$ of the flotation collar of the nauplii of Peltogaster (a, e), Lernaeodiscus (b, f), Parthenopea (c, g) (from [7; Fig. 3d]), and Sacculina (d). Designations: cfl, caudal process of the flotation collar; ne, naupliar eye.

collar begins to form earlier [48, 69]. The flotation collar is fixed on the attachment ridge; if the collar gets torn off, pores are visible along the ridge. Pores were found in different parts of the attachment ridge in nauplii of B. tenellus, Peltogaster paguri, and P. reticulata [33, 48, 66], no pores were found in Peltogasterella [57].

The flotation collar is likely to be a plesiomorphic trait [33]. It improves the hydrodynamic properties of the nauplius and facilitates a greater dispersal of larvae. Previously, the presence of the flotation collar was considered a synapomorphy of the families Peltogastridae and Lernaeodiscidae, which form a monophyletic clade [33]. At present, the presence of the collar confirms the uniting of these two families, but is not their synapomorphy, since species of the new families Peltogasterellidae and Parthenopeidae also have the collar [7, 57].

\section{Eyes (Fig. 2)}

A pigmented medial eye that provides positive phototaxis is present in the nauplii and cyprids of most of the described rhizocephalan species. Interestingly, larvae of the genera Peltogaster and Briarosaccus with the most developed flotation collar have no naupliar eye and lack phototaxis (Fig. 2a) [19, 29, 48, 66]. In species with a thin collar, i.e., with partial reduction of this structure, the larva develops a naupliar eye and positively reacts to light (Fig. 2b).

Compound eyes are characteristic of the cypris larvae of free-living barnacles and appear in them as early as the last naupliar stage; among rhizocephalans they are found only in Parthenopea subterranea. The presence of compound eyes is regarded as a plesiomorphic trait [7]. The unique features of the larvae of $P$. subterranea, especially the unusual flotation collar in nauplii and compound eyes in cyprids, confirm the separation of the genus Parthenopea into a family, the Parthenopeidae $[7,34]$.

\section{Dorsal Setae of the Carapace (Fig. 3)}

The carapace of nauplii bears dorsal setae, which are probably the precursors of the lattice organs of cyprids $[41,56]$. In peltogastrid-type nauplii, there are usually six pairs of dorsal setae: three anterior pairs and three posterior pairs. The large setae of the second pair are U-shaped and more curved in the genera $\mathrm{Bri}$ arosaccus and Peltogaster [48, 66] (Figs. 3a, 3c). The U-shaped setae are another feature confirming the merging of the families Peltogastridae and Lernaeodiscidae. In peltogastrid-type cyprids, the lattice organs of the second pair are crescent-shaped, which confirms the homology of these structures [47, 48, 56, 57] (Fig. 3b). Minute setae 2a may be the precursors of 
(a)
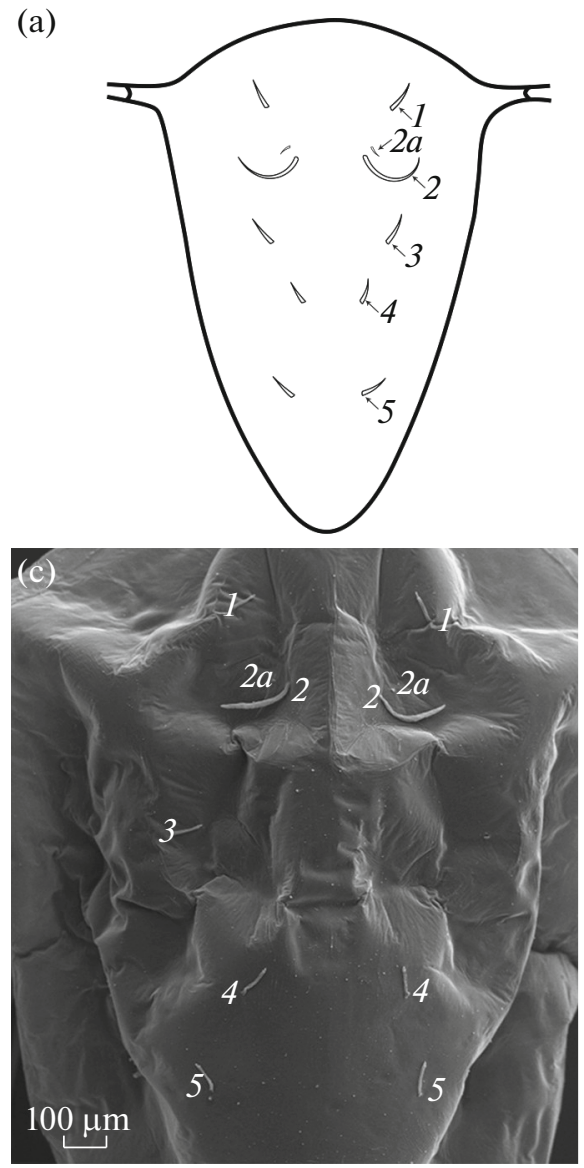

(b)
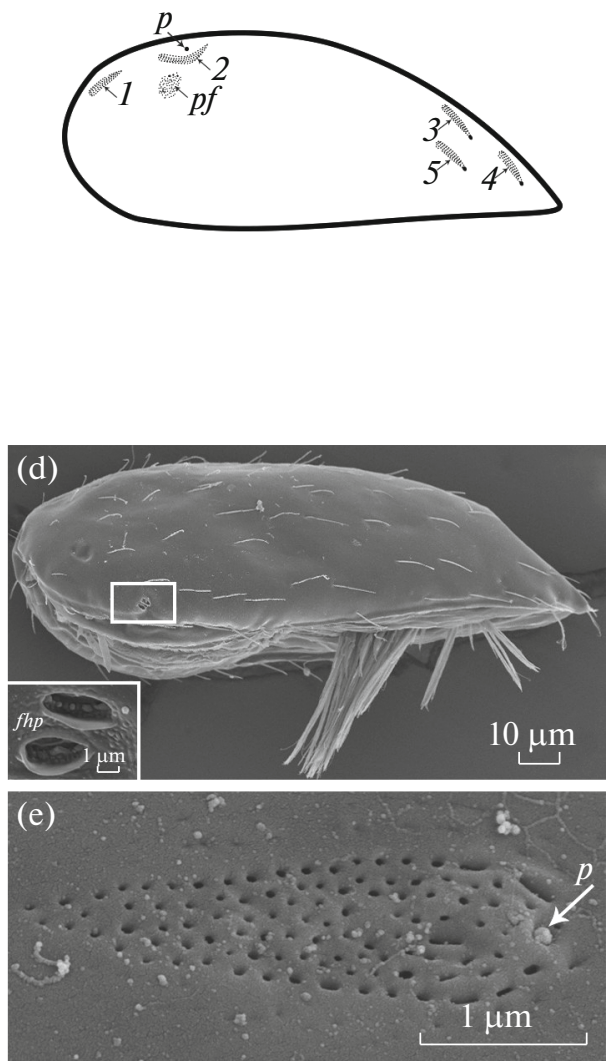

Fig. 3. The carapace of the peltogastrid-type nauplius (a, c), cypris larva (b, d), and the lattice organ of the fifth pair (e). Designations: $f h p$, pores of glands of frontolateral horns (inset); $p$, a terminal pore of lattice organ; $p f$, porefield; (1-5) dorsal setae (a, c) and corresponding lattice organs (b). Figure 3c from [47; Fig. 13C], reproduced with permission from Elsevier.

the porefields, which are always located near the second pair of lattice organs [56]. The second pair of setae usually appears at the second naupliar stage; however, in Peltogasterella gracilis, they are visible as early as at the first stage [57].

Some sacculinid-type nauplii have fewer setae: two pairs in Parasacculina sinensis [9], four pairs in Polyascus polygeneus [56], but six pairs in Heterosaccus papillosus [54]. Dorsal setae usually terminate in a pore, which may be homologous to the large terminal pore of lattice organs.

\section{Frontolateral Horns (Fig. 4)}

The frontolateral horns of the nauplii represent a synapomorphy of all Cirripedia [25, 66]. Pores of large unicellular glands open at the ends of each horn. At the first naupliar stage, the larva has one subterminal seta (Fig. 4a). Starting at the second stage, the openings at the ends of the horns are rimmed with a cuticular fringe (Figs. 4b-4e); larvae of Peltogaster, Briarosaccus, and Lernaeodiscus (Figs. 4b, 4c) have two subterminal setae on the horns, external and internal ones
[19, 47, 48, 66], nauplii of Peltogasterella (Fig. 4d) have only one subterminal seta [57].

In nauplii of Peltogasterella and Lernaeodiscus, the frontolateral horns are divided by grooves (sutures) into three parts, or "segments" (Figs. 4c, 4d) [47, 57]. In larvae of Peltogaster and Briarosaccus the horns are longer and the distal part is bisected by a less distinct groove. At later stages, the number of grooves in the proximal part of the horns increases and the number of "segments" may be up to five (Fig. 4b) [48, 66].

Earlier, it was thought that the horns of sacculinidtype larvae are short and unsegmented [10, 54], but photographs in papers show that these horns also have a proximal groove and, accordingly, are divided into two "segments" (Fig. 4e). Their distal groove is indistinct $[9,54,58,59]$. The subterminal setae on the frontolateral horns are absent in sacculinid-type nauplii; however, the horns terminate in two processes (spines) (Fig. 4e). It is not yet clear whether these setae and processes are homologous. Either they are different structures, or the distal segments of the horns of sacculinid-type larvae are reduced so that the subterminal setae become terminal processes. In this case, 

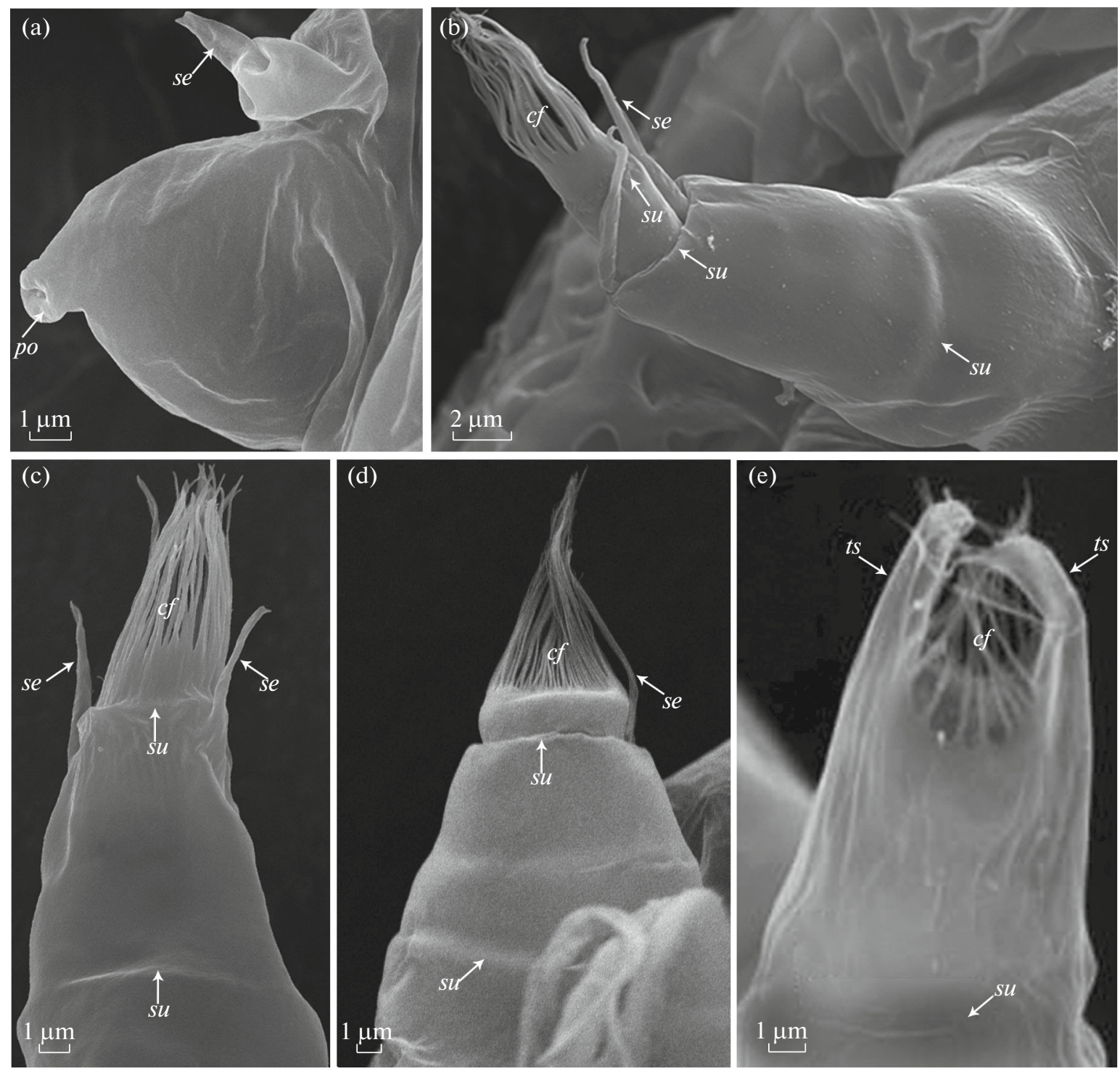

Fig. 4. The frontolateral horns of the nauplii of Lernaeodiscus rybakovi (a, c) (from [47; Figs. 8C, 10D], reproduced with permission from Elsevier); Peltogaster reticulata (b) (from [48; Fig. 9H], reproduced with permission from copyright holder); Peltogasterella gracilis (d) and Heterosaccus papillosus (e) (from [54; Fig. 5C], reproduced with permission). Designations: cf, cuticular fringe; $p o$, pore; $s e$, subterminal setae; $s u$, suture; $t$, terminal processes (spines).

the armament of the frontolateral horns in the peltogastrid-type nauplii is a plesiomorphic state.

\section{The Hind Body of the Nauplius (Fig. 5)}

The hind body of the nauplius gradually becomes segmented, naupliar stages can be distinguished by the segmentation pattern (Fig. 5a). Segmentation reflects the formation of thoracic segments of the future cypris larva. At the fifth stage, the thoracic appendages of the cyprid are clearly visible under the integument of the nauplius. In a scanning electron microscope, small denticles marking the orientation of the thoracic segments are visible as a longitudinal strip at the third naupliar stage and oblique strips at the fourth and fifth stages (Figs. 5b, 5c). The timing of the appearance of such segmentation slightly varies in different species $[5,6,47,48,54,57,66]$.

The hind body of the nauplius ends in a furca with small denticles (spinules) on the furcal sides in the late naupliar stages (Fig. 5d). In sacculinid-type nauplii, the denticles are less pronounced; at the same time, there is a small tubercle between the furcal rami, which is not characteristic of the peltogastrid-type larvae [6, $9,54,58,59]$.

\section{Appendages}

Like all Cirripedia, the rhizocephalan nauplius has three pairs of appendages-uniramous antennules, 


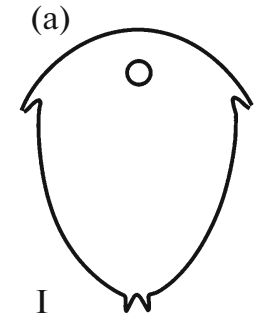

$100 \mathrm{~mm}$
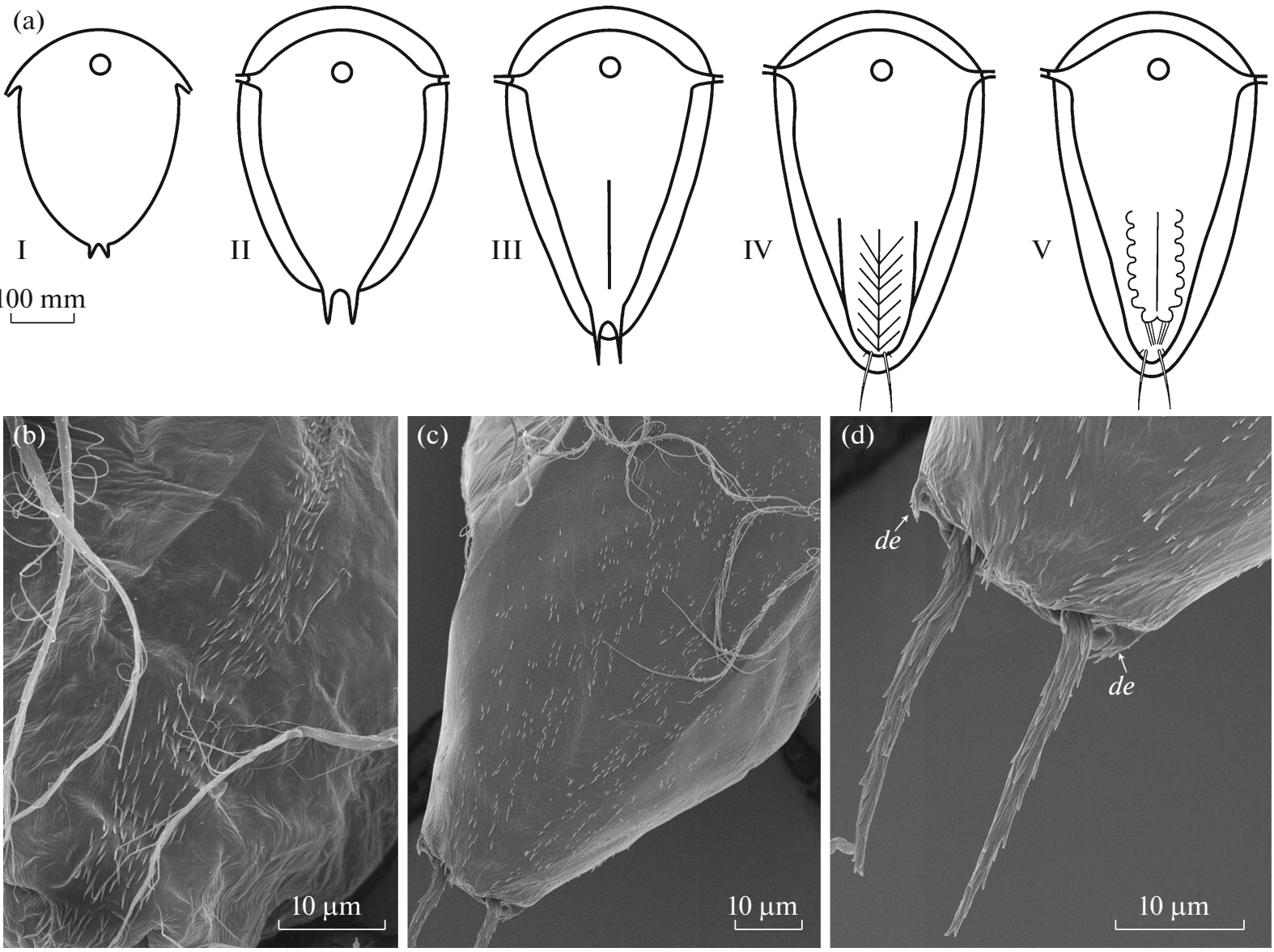

Fig. 5. Naupliar stages I-V (a); denticles marking the orientation of the thoracic segments of nauplius III (b), IV (c) and the furca (d). Designation: $d e$, denticles on the sides of the furca.

biramous antennae, and mandibles (Figs. 1b-1d). The antennules bear five setae. At the fourth stage, the first seta is reduced. In the late nauplii of some species, a small spine was found near the fifth seta $[47,48,54$, $57,66]$. It was suggested that this is the sixth rudimentary seta [57]. In Sacculina carcini, such a spine was not found in all examined specimens; therefore, the authors believe that it cannot be considered a true rudimentary seta [58]. In Lernaeodiscus rybakovi, S. carcini, and Heterosaccus papillosus, the fifth antennular seta is located on the middle segment at the early stages; later it is shifted to the distal segment $[54,58]$. A similar "jump" of the seta was previously described in barnacle larvae [18]. At the last stages, the attachment disk of the future cypris larva develops inside the middle segment of the antenna, so the segment becomes swollen.

The antenna of rhizocephalan nauplii has an eightsegmented, but not a seven-segmented exopod, as thought previously [48]. Some researchers did not take into account a small distal segment [57], while others missed the last proximal segment, which gradually increases during larval development [54]. All known species have five setae on the antennal exopod and three setae on the endopod; an exception is Parthenopea subterranea, in which the nauplius bears only two setae on the antennal endopod [7].

The seta at the basis of the antenna is long in nauplii of Peltogaster, Briarosaccus, and Lernaeodiscus [19, 47, 48, 66] and much shorter in larvae of Peltogasterella [57]. In sacculinid-type larvae and in nauplii of P. subterranea, the antennal basis is unarmed. This seta is possibly a vestige of the gnathobase found in planktotrophic nauplii. Its presence is apparently a plesiomorphic trait [57]. The naupliar mandible has four setae on the exopod and two setae on the endopod.

\section{Sex of Larvae}

Rhizocephalans with kentrogonid type of development are apparently the only group of crustaceans in which there is sexual dimorphism of larvae. The nauplii mainly differ in size: male larvae are generally larger than female ones. Usually, their sizes slightly overlap [9, 47], although this can only be established with certainty in the case of unisexual larval generations. Minor morphological differences are sometimes observed. As an example, in Heterosaccus papillosus, 
the anterior margin of male nauplii III-V is more convex than that of female nauplii [54]. In Polyascus pla$n u s$, the hind body is narrower in female nauplii than in males. The first seta and head shield of male nauplii have pores, female larvae lack pores [59].

Male cyprids of parasites with kentrogonid type of development are also larger than female ones, while their sizes can also overlap; therefore, size is not the only criterion for determining the sex of cypris larvae. Examples of nonoverlapping sizes can be explained by insufficient number of measurements or incorrect sex determination of larvae $[5,54,55,59]$.

As mentioned above, each externa produces several (sometimes many) generations of larvae during the breeding season. The ratio of male to female larvae in one generation varies depending on the season and is determined by the stage of the parasite's reproductive cycle. In the breeding season when the proportion of juvenile externae in population is high, male or mixed generations with a large number of male larvae prevail. This leads to multiple fertilizations and the appearance of more embryos and larvae. In Peter the Great Bay (the Sea of Japan), this usually occurs in summer. At the end of the breeding season (in fall), female larvae capable of infesting new hosts begin to prevail in broods of Polyascus polygeneus, Lernaeodiscus rybakovi, and Peltogaster reticulata [3, 47, 48]. In Hong Kong, exclusively male larvae of Parasacculina sinensis occur in summer, while female larvae predominate in winter [9]. At the same time, in Taiwan, mostly female larvae of Polyascus planus are found in summer and male larvae in winter [59]. In California, male L. porcellanae larvae predominate in the winter months; and female larvae, in summer [55]. In Sacculina carcini from the English Channel, male larvae predominate in late spring and early summer, when juvenile externae are found, while female larvae are more numerous in early fall $[20,30]$.

\section{Structure of Male and Female Cypris Larvae}

The size of rhizocephalan cypris larvae is smaller than that of nauplii. The surface of the carapace of peltogastrid-type cyprids is densely covered with rather long setae and pores (Fig. 3d) [14, 47, 48, 57, 66]. In sacculinid-type larvae, setae and pores on the carapace are less common [9, 62]. Two slit-like pores are visible on either side of the carapace, the glands of the frontolateral horns open through these pores (Fig. 3d, inset).

In cypris larvae of rhizocephalans with kentrogonid type of development, five pairs of lattice organs (two anterior pairs and three posterior ones) are usually located on the surface of the carapace (Figs. 3b, 3e). The second pair is crescent-shaped in peltogastrid type of larvae and it is almost straight in sacculinidtype cyprids. The rest of the pairs are straight in all species; the fifth pair is on the side of the third or fourth pair $[9,41,47,48,56,57,59,66]$. The arrange- ment of the lattice organs relative to the midline of the carapace slightly differs among species. As an example, in Polyascus planus, the lattice organs of the second pair are markedly displaced to the ventral side of the carapace [59]. In male cyprids of Heterosaccus lunatus, the lattice organs of the fourth and fifth pairs merge, while in female cyprids they are separate [70].

Peltogastrid-type larvae usually have terminal pores at the end of the lattice organs: in the first and second pairs anteriorly and in the thrid-fifth pairs posteriorly (Fig. 3e). In larvae of sacculinid type, the terminal pores are more often found only on the anterior pairs of lattice organs [56, 59, 70]. Cyprids of $H$. lunatus lack pores on all lattice organs [62]. In addition to the lattice organs, the porefields are often observed on the surface of the carapace. The lattice organs and porefields of the cypris larva perform a chemosensory function [27], as the dorsal setae of the nauplii also apparently do.

The cypris larva of Rhizocephala has six pairs of biramous thoracopods and paired caudal processes that are used for flotation. The antennule is of greatest interest (Fig. 6); the cypris larvae seek and search the substrate using it. In rhizocephalans with kentrogonid type of development, the antennules of male and female cyprids significantly differ, which is associated with their different functions.

The antennule consists of four segments. The third segment forms an attachment disk, by means of which the larva fixes itself on the host's body or on the surface of the externa. The disk is covered with cuticular villi and rare pores, which are probably the openings of the antennular glands [62]. The perimeter of the disk is bordered by a cuticular fold or "skirt," which is more pronounced in female cyprids. A flap-like extension of the posterior (proximal) edge of the attachment disk is found in male larvae of Heterosaccus lunatus, H. papillosus, H. californicus, and Peltogaster reticulata [48, 54, 62, 70] (Fig. 6b), while in Lernaeodiscus rybakovi it was observed in female cyprids [47] (Figs. 6d, 6g). The second segment has a postaxial sensory seta; while the attachment disk bears axial and postaxial sensory setae, their number and location differ among genera and families.

Male cyprids of many rhizocephalans have a socalled spinous process at the distal edge of the attachment disk. It is located inside the pore of a large unicellular gland. This process was found in Sacculina carcini, H. lunatus, H. californicus, H. papillosus, Parasacculina sinensis, and P. planus $[9,14,21,53,54,59$, 62], as well as in Sacculina pugettiae (Fig. 6c). Male cyprids of the Peltogastridae lack the spinous process $[14,47,48,53,57,66]$. The open-ended seta located in the anterior region of the attachment disk of Peltogasterella sulcata and Peltogaster paguri was erroneously called the spinous process [14]. It is usually almost invisible, but may be present in larvae of both sexes (Figs. 6b, 6e). The presence of the spinous pro- 
(a)

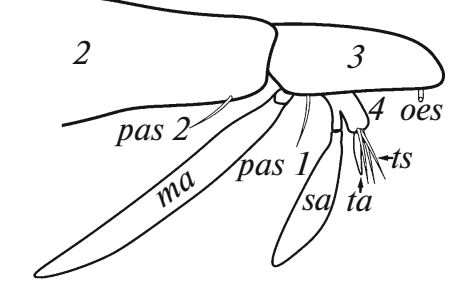

(d)
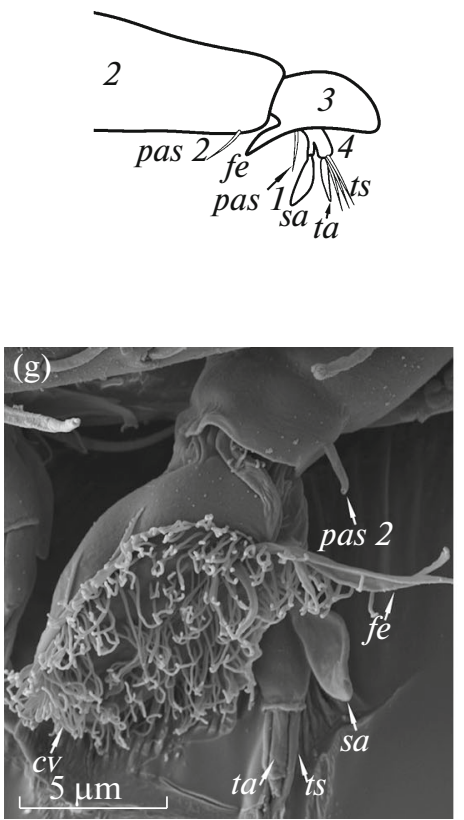

(b)

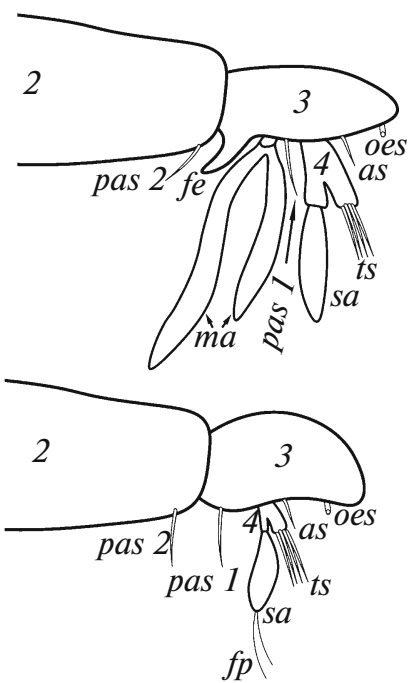

(e)

(c)

(f)
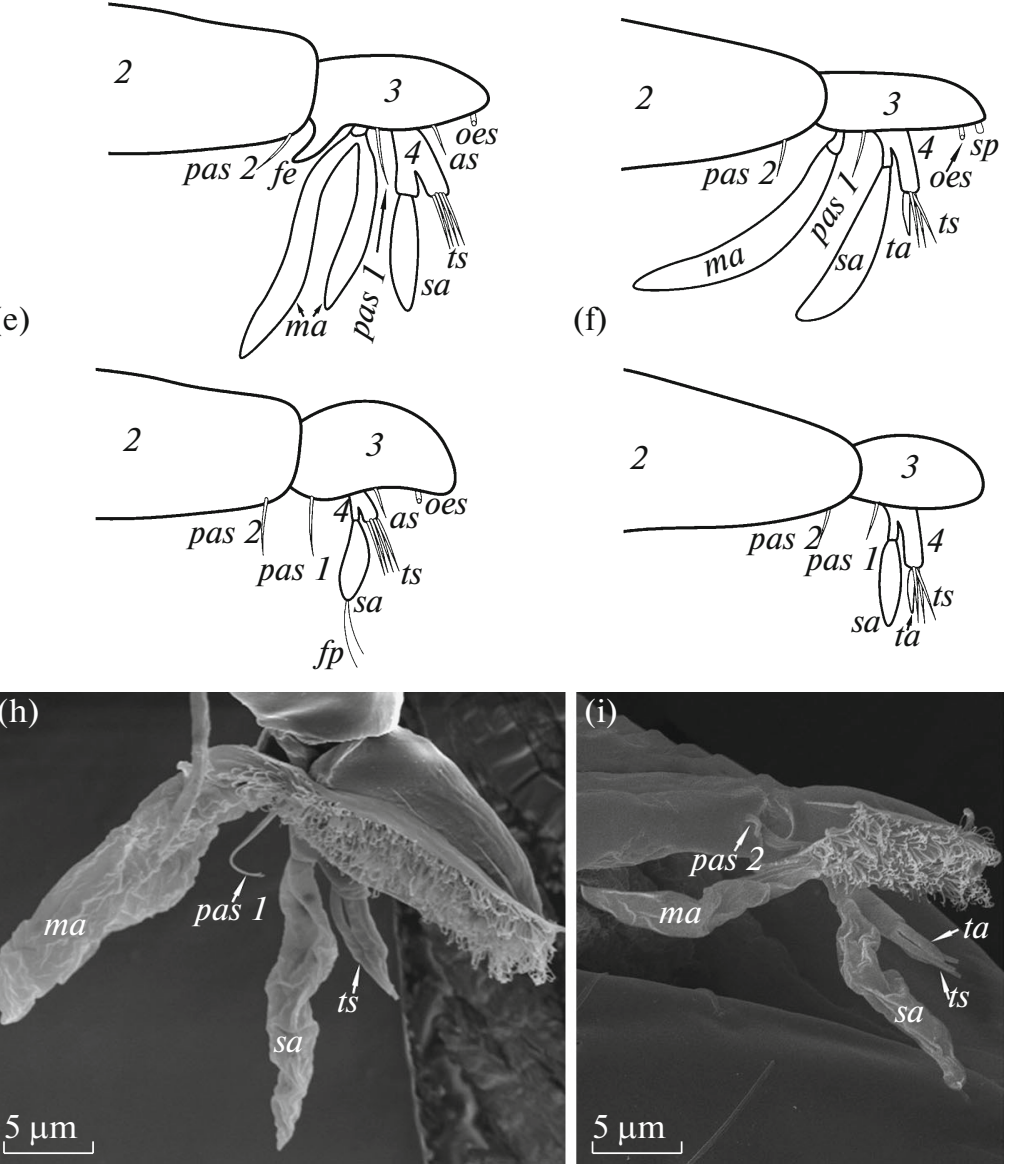
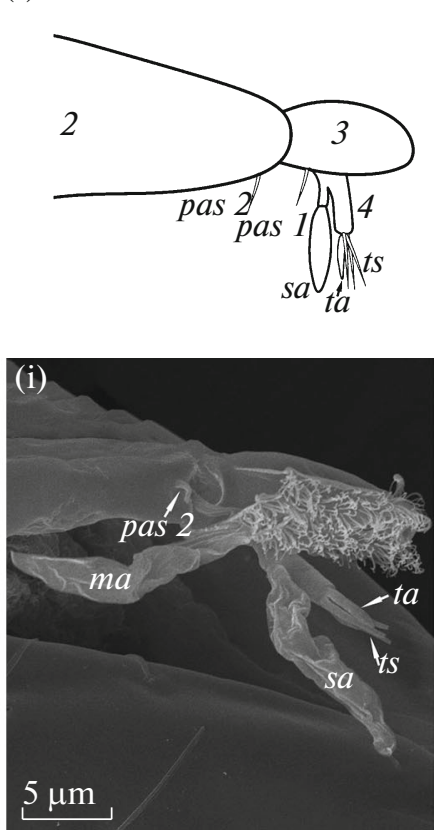

Fig. 6. The structure of the antennule of the male $(\mathrm{a}-\mathrm{c}, \mathrm{h}, \mathrm{i})$ and female $(\mathrm{d}-\mathrm{f}, \mathrm{g})$ cypris larvae of Lernaeodiscus rybakovi (a, d, $\mathrm{g})$, Peltogaster reticulata (b, e, h) and Sacculina pugettiae (c, f, i). Designations: as, axial sensory seta; $c v$, cuticular villi; $f e$, flap-like extension; $f p$, filamentous processes; $m a$, male aesthetask; oes, open-ended sensory seta; pas 1, postaxial sensory seta 1; pas2, postaxial sensory seta 2 ; $s a$, subterminal aesthetask; $s p$, spinous process; $t a$, terminal aesthetask; $t s$, terminal setae; $(2-4)$ antennular segments.

cess along with this seta in male larvae of $H$. lunatus [62] and S. pugettiae (Fig. 6c) indicates that these are different structures. Both are characteristic only of rhizocephalan larvae [14].

Male and female larvae of rhizocephalan crustaceans differ in the number and size of antennular aesthetasks, which are special thickened sensory setae. Male cyprids usually have a large male aesthetask at the proximal edge of the antennular disk. The fourth segment of the antennula has a rather large subterminal aesthetask (Figs. 6a-6c, 6h, 6i). Female cyprids lack the male aesthetask on the antennular disk but have a shorter subterminal aesthetask on the fourth segment (Figs. 6d-6f, 6g). Larvae of both sexes usually have a short terminal aesthetask (or sac-shaped seta) at the end of the fourth segment and three open-ended setae (Fig. 6).

Among different genera and even species of Rhizocephala, the antennular disk of cyprids exhibits char- acteristic features. The large male aesthetask in larvae of the genus Peltogaster is divided into two lobes (Figs. 6b, 6h) [14, 48], while in cyprids of the genera Briarosaccus, Lernaeodiscus, Peltogasterella, Sacculina, and Polyascus it is unilobed (Figs. 6a, 6c, 6i) [14, $47,53,57,59]$. The male aesthetask is absent in cyprids of Heterosaccus lunatus and H. papillosus and is reduced in $H$. californicus [54, 62], which is probably an apomorphic character of this genus [70]. The subterminal aesthetask of female cypris larvae of the genus Peltogaster ends in two filamentous processes that are not found in larvae of other genera (Fig. 6e). The postaxial sensory seta on the third antennular segment in larvae of Peltogaster reticulata is slightly bifurcated (Fig. 6h), while in P. paguri it is even divided into three tips. At the same time, the cyprid of $P$. reticulata has an additional axial sensory seta (Figs. 6b, 6e), which is probably absent in larvae of $P$. paguri $[14,48]$. The posterior sensory seta on the cuticular "skirt" was only found in cyprids of the genus Peltogasterella [57]. 


\section{CONCLUSIONS}

The morphology and ultrastructure of rhizocephalan larvae often provide more important information for the taxonomy and phylogeny of Rhizocephala than the morphology and anatomy of the externa. Despite the fact that the larvae live and evolve in the pelagic zone, i.e., in a different environment, compared to the adults, their structure is largely determined by their taxonomic position. The larvae of each rhizocephalan family and even genus have characteristic features. The description of larval development is an essential component of a comprehensive study of Rhizocephala.

\section{FUNDING}

This review study was funded by the Russian Foundation for Basic Research (project no. 20-04-00097).

\section{COMPLIANCE WITH ETHICAL STANDARDS}

The authors declare that they have no conflict of interest. This article does not contain any studies involving animals or human participants performed by any of the authors.

\section{OPEN ACCESS}

This article is licensed under a Creative Commons Attribution 4.0 International License, which permits use, sharing, adaptation, distribution and reproduction in any medium or format, as long as you give appropriate credit to the original author(s) and the source, provide a link to the Creative Commons licence, and indicate if changes were made. The images or other third party material in this article are included in the article's Creative Commons licence, unless indicated otherwise in a credit line to the material. If material is not included in the article's Creative Commons licence and your intended use is not permitted by statutory regulation or exceeds the permitted use, you will need to obtain permission directly from the copyright holder. To view a copy of this licence, visit http://creativecommons.org/licenses/by/4.0/.

\section{REFERENCES}

1. Kashenko, S.D. and Korn, O.M., Adaptive responses of the larvae of cirripede barnacle Peltogasterella gracilis to changes in seawater temperature and salinity, Russ. J. Mar. Biol., 2002, vol. 28, no. 5, pp. 317-323.

2. Kashenko, S.D. and Korn O.M., Combined effects of seawater temperature and salinity on development of the larvae of the rhizocephalan Peltogaster reticulatus (Crustacea: Cirripedia), Russ. J. Mar. Biol., 2003, vol. 29, no. 3, pp. 150-155.

3. Korn, O.M., Shukalyuk, A.I., Trofimova, A.V., and Isaeva V.V., Reproductive stage of the life cycle in the rhizocephalan barnacle Polyascus polygenea (Crustacea: Cirripedia), Russ. J. Mar. Biol., 2004, vol. 30, no. 5, pp. 328-340.
4. Korn, O.M., Rybakov, A.V., and Høeg, J.T., Larval development in a rhizocephalan barnacle Peltogasterella gracilis, Russ. J. Mar. Biol., 1999, vol. 25, no. 2, pp. 141-143.

5. Korn, O.M. and Rybakov, A.V., Larval development in the rhizocephalan barnacle Sacculina pilosella, Russ. J. Mar. Biol., 2001, vol. 27, no. 3, pp. 177-179.

6. Korn, O.M., Rybakov, A.V., and Kashenko, S.D., Larval development of the rhizocephalan Sacculina polygenea (Crustacea: Cirripedia) Russ. J. Mar. Biol., 2000, vol. 26, no. 5, pp. 373-377.

7. Rybakov, A.V. and Høeg, J.T., The taxonomic position of rhizocephalan crustaceans of the genus Parthenopea Kossmann, 1874 (Cirripedia: Rhizocephala) with validation of a new family, Parthenopeidae fam. nov., Russ. J. Mar. Biol., 2013, vol. 39, no. 5, pp. 357-362.

8. Andersen, M.L., Bohn, M., Høeg J.T., and Jensen, P.G., Cyprid ultrastructure and adult morphology in Ptychascus barnwelli, new species, and P. glaber (Cirripedia: Rhizocephala), parasites on semiterrestrial crabs, J. Crustacean Biol., 1990, vol. 10, no. 1, pp. 20-28.

9. Chan, B.K.K., Poon, D.Y.N., and Walker, G., Distribution, adult morphology, and larval development of Sacculina sinensis (Cirripedia: Rhizocephala: Kentrogonida) in Hong Kong coastal waters, J. Crustacean Biol., 2005, vol. 25, no. 1, pp. 1-10.

10. Collis, S.A. and Walker, G., The morphology of the naupliar stages of Sacculina carcini (Crustacea: Cirripedia: Rhizocephala), Acta Zool., 1994, vol. 75, no. 4, pp. 297-303.

11. Glenner, H. and Hebsgaard, M.B., Phylogeny and evolution of life history strategies of the parasitic barnacles (Crustacea, Cirripedia, Rhizocephala), Mol. Phylogenet. Evol., 2006, vol. 41, pp. 528-538.

12. Glenner, H. and Høeg, J.T., Metamorphosis in the Cirripedia Rhizocephala and the homology of the kentrogon and trichogon, Zool. Scr., 1994, vol. 23, no. 2, pp. $161-173$.

13. Glenner, H. and Høeg, J.T., A new motile, multicellular stage involved in host invasion by parasitic barnacles (Rhizocephala), Nature, 1995, vol. 377, pp. 147-150.

14. Glenner, H., Høeg, J.T., Klysner, A., and Larsen, B.B., Cypris ultrastructure, metamorphosis and sex in seven families of parasitic barnacles (Crustacea: Cirripedia: Rhizocephala), Acta Zool., 1989, vol. 70, no. 4, pp. 229-242.

15. Glenner, H., Høeg, J.T., O’Brien, J.J., and Sherman, T.D., Invasive vermigon stage in the parasitic barnacles Loxothylacus texanus and L. panopaei (Sacculinidae): closing of the rhizocephalan life cycle, Mar. Biol., 2000, vol. 136, pp. 249-257.

16. Glenner, H., Høeg, J.T., Rees, D.J, and Schubart, C.D., Phylogenetic analyses suggest a single origin of freshwater barnacles, in Recent Advances in Freshwater Crustacean Biodiversity and Conservation, Boca Raton: CRC Press, 2021, ch. 2, pp. 3-18.

17. Glenner, H., Høeg, J.T., Stenderup, J., and Rybakov, A.V., The monophyletic origin of a remarkable sexual system in akentrogonid rhizocephalan parasites: a molecular and larval structural study, Exp. Parasitol., 2010, vol. 125 , pp. 3-12. 
18. Grygier, M.J., Developmental patterns and hypotheses of homology in the antennules of thecostracan nauplius larvae (Crustacea), Acta Zool., 1994, vol. 75, no. 3, pp. 219-234.

19. Hawkes, C.R., Meyers, T.R., and Shirley, T.C., Larval biology of Briarosaccus callosus Boschma (Cirripedia: Rhizocephala), Proc. Biol. Soc. Wash., 1985, vol. 98, no. 4, pp. 935-944.

20. Høeg, J.T., Cypris settlement, kentrogon formation and host invasion in the parasitic barnacle Lernaeodiscus porcellanae (Müller) (Crustacea: Cirripedia: Rhizocephala), Acta Zool., 1985, vol. 66, no. 1, pp. 1-45.

21. Høeg, J.T., Male cypris metamorphosis and a new male larval form, the trichogon, in the parasitic barnacle Sacculina carcini (Crustacea: Cirripedia: Rhizocephala), Philos. Trans. R. Soc. Lond. B., 1987, vol. 317, no. 1183 , pp. 47-63.

22. Høeg, J.T., "Akentrogonid" host invasion and an entirely new type of life cycle in the rhizocephalan parasite Clistosaccus paguri (Thecostraca: Cirripedia), J. Crustacean Biol., 1990, vol. 10, no. 1, pp. 37-52.

23. Høeg, J.T., Rhizocephala, in Microscopic Anatomy of Invertebrates, New York: Alan Liss, 1992, vol. 9, pp. 313-345.

24. Høeg, J.T., The biology and life cycle of the Rhizocephala (Cirripedia), J. Mar. Biol. Assoc. U. K., 1995, vol. 75 , pp. $517-550$.

25. Høeg, J.T., Chan, B.K.K., and Martin, J.W., Introduction to the Thecostraca, in Atlas of Crustacean Larvae, Baltimore: Johns Hopkins Univ. Press, 2014, pp. 97-99.

26. Høeg, J.T., Chan, B.K.K., and Rybakov, A.V., Rhizocephala, in Atlas of Crustacean Larvae, Baltimore: Johns Hopkins Univ. Press, 2014, pp. 111-113.

27. Høeg, J., Hosfeld, B., and Jensen, P.G., TEM studies of the lattice organs of cirripede cypris larvae (Crustacea, Thecostraca, Cirripedia), Zoomorphology, 1998, vol. 118, pp. 195-205.

28. Høeg, J.T., Lagersson, N.C., and Glenner, H., The complete cypris larva and its significance in thecostracan phylogeny, in Evolutionary Developmental Biology of Crustacea, Crustacean Issues, vol. 15, Lisse, The Netherlands: A.A. Balkema, 2004, pp. 197-215.

29. Høeg, J.T. and Lützen, J., Crustacea Rhizocephala, Marine Invertebrates of Scandinavia, Norway: Norwegian Univ. Press, 1985, vol. 6.

30. Høeg, J.T. and Lützen, J., Life cycle and reproduction in the Cirripedia Rhizocephala, Oceanogr. Mar. Biol. Annu. Rev., 1995, vol. 33, pp. 427-485.

31. Høeg, J.T. and Lützen, J., Super-ordre des Rhizocéphales (Rhizocephala F. Müller, 1862), in Traité de zoologie, vol. 7, fasc. 2: Crustacés: Géneralités (suite) et systématique (1re partie), Paris: Masson, 1996, pp. 541568.

32. Høeg, J.T. and Møller, O.S., When similar beginnings lead to different ends: constraints and diversity in cirripede larval development, Invertebr. Reprod. Dev., 2006, vol. 49 , no. 3 , pp. $125-142$.

33. Høeg, J.T., Møller, O.S., and Rybakov, A.V., The unusual floatation collar around nauplii of certain parasitic barnacles (Crustacea: Cirripedia: Rhizocephala), Mar. Biol., 2004, vol. 144, pp. 483-492.
34. Høeg, J.T., Noever, C., Rees, D.J., et al., A new molecular phylogeny-based taxonomy of parasitic barnacles (Crustacea: Cirripedia: Rhizocephala), Zool. J. Linn. Soc., 2020, vol. 190, no. 2, pp. 632-653.

35. Høeg, J.T., Pérez-Losada, M., Glenner H., et al., Evolution of morphology, ontogeny and life cycles within the Crustacea Thecostraca, Arthropod Syst. Phylog., 2009, vol. 67, no. 2, pp. 199-217.

36. Høeg, J.T., Rees, D.J., Jensen, P.C., and Glenner, H., Unravelling the evolutions of the Rhizocephala: a case study for molecular-based phylogeny in the parasitic Crustacea, in Parasitic Crustacea: State of Knowledge and Future Trends, Zoological Monographs, vol. 3, Berlin: Springer-Verlag, 2019, pp. 387-419.

37. Høeg, J.T. and Rybakov, A.V., Cypris larvae in Polysaccus mediterraneus and Mycetomorpha vancouverensis: Their importance in analyzing the phylogeny and sexual evolution of parasitic barnacles (Crustacea: Cirripedia: Rhizocephala), Isr. J. Ecol. Evol., 2007, vol. 53, pp. 9-31.

38. Isaeva, V.V., Shukalyuk, A.I., Korn, O.M., et al., Development of primordial externae in the colonial interna of Polyascus polygenea (Crustacea: Cirripedia: Rhizocephala), Crustacean Res., 2004, no. 33, pp. 61-71.

39. Isaeva, V.V., Shukalyuk, A.I, Trofimova, A.V., et al., The structure of colonial interna in Sacculina polygenea (Crustacea: Cirripedia: Rhizocephala), Crustacean Res., 2001, no. 30, pp. 134-147.

40. Itô, T., Naupliar development of Hansenocaris furcifera Itô (Crustacea: Maxillopoda: Facetotecta) from Tanabe Bay, Japan, Publ. Seto Mar. Biol. Lab., 1990, vol. 34, nos. 4-6, pp. 201-224.

41. Jensen, P.G., Moyse, J., Høeg, J., and Al-Yahya, H., Comparative SEM studies of lattice organs: putative sensory structures on the carapace of larvae from Ascothoracida and Cirripedia (Crustacea Maxillopoda Thecostraca), Acta Zool., 1994, vol. 75, no. 2, pp. 125142.

42. Kashenko, S.D. and Korn, O.M., Effects of temperature and salinity on the larvae of two species of rhizocephalan (Crustacea: Cirripedia), Invertebr. Reprod. Dev., 2002, vol. 41, no. 1-3, pp. 179-184.

43. Kashenko, S.D., Korn, O.M., and Rybakov, A.V., Effects of temperature and salinity on the larvae of $\mathrm{Saccu}$ lina polygenea (Crustacea: Cirripedia: Rhizocephala), Crustacean Res., 2002, vol. 31, pp. 9-17.

44. Kobayashi, M., Wong, Y.H., Oguro-Okano, M., et al., Identification, characterization, and larval biology of a rhizocephalan barnacle, Sacculina yatsui Boschma, 1936, from northwestern Japan (Cirripedia: Sacculinidae), J. Crustacean Biol., 2018, vol. 38, no. 3, pp. 329340 .

45. Kolbasov, G.A., Petrunina, A.S., Dreyer, N., et al., Naupliar development of Facetotecta (Crustacea: Thecostraca) and the nature of the first nauplius instar in the Crustacea: Pro et contra the Hexanauplia concept, Org. Diversity Evol., 2021, vol. 21, pp. 209-230.

46. Korn, O.M., Naupliar evidence for cirripede taxonomy and phylogeny, in New Frontiers in Barnacle Evolution, Crustacean Issues, vol. 10, Rotterdam: A.A. Balkema, 1995, pp. 87-122. 
47. Korn, O.M., Golubinskaya, D.D., Rees, D.J., et al., Phylogenetic position, complete larval development and larval sexual dimorphism in a rhizocephalan barnacle, Lernaeodiscus rybakovi sp. nov. (Cirripedia: Rhizocephala: Peltogastridae), parasitizing the crab Pachycheles stevensii Stimpson, 1858 (Decapoda: Anomura: Porcellanidae), Zool. Anz., 2020, vol. 287, pp. 178-197.

48. Korn, O.M., Golubinskaya, D.D., and Sharina, S.N., The parasitic barnacle Peltogaster reticulata Shiino, 1943 (Rhizocephala, Peltogastridae) from Russian waters of the Sea of Japan: Morphological description, molecular identification and complete larval development, Zootaxa, 2020, vol. 4768, no. 1, pp. 6-24.

49. Lützen, J., Itani, G., Jespersen, Á., et al., On a new species of parasitic barnacle (Crustacea: Rhizocephala), Sacculina shiinoi sp. nov., parasitizing Japanese mud shrimps Upogebia spp. (Decapoda: Thalassinidea: Upogebiidae), including a description of a novel morphological structure in the Rhizocephala, Zool. Sci., 2016, vol. 33, pp. 204-212.

50. Martin, J.W. and Davis, G.E., An Updated Classification of the Recent Crustacea, Los Angeles: Nat. Hist. Mus. Los Angeles County Sci. Ser., no. 39, 2001.

51. Martin, J.W., Olesen, J., and Høeg, J.T., Introduction, in Atlas of Crustacean Larvae, Baltimore: Johns Hopkins Univ. Press, 2014, pp. 1-7.

52. Moyse, J., Larvae of lepadomorph barnacles, in Barnacle Biology, Rotterdam: A.A. Balkema, 1987, pp. 329362.

53. Moyse, J., Høeg, J.T., Jensen, P.G., and Al-Yahya, H.A.H., Attachment organs in cypris larvae: using scanning electron microscopy, in New Frontiers in Barnacle Evolution, Crustacean Issues, vol. 10, Rotterdam: A.A. Balkema, 1995, pp. 153-177.

54. Ponomarenko, E.A., Korn, O.M., and Rybakov, A.V., Larval development of the parasitic barnacle Heterosaccus papillosus (Cirripedia: Rhizocephala: Sacculinidae) studied under laboratory conditions, J. Mar. Biol. Assoc. U. K., 2005, vol. 85, pp. 921-928.

55. Ritchie, L.E. and Høeg, J.T., The life history of Lernaeodiscus porcellanae (Cirripedia: Rhizocephala) and co-evolution with its porcellanid host, J. Crustacean Biol., 1981, vol. 1, no. 3, pp. 334-347.

56. Rybakov, A.V., Høeg, J.T., Jensen, P.G., and Kolbasov, G.A., The chemoreceptive lattice organs in cypris larvae develop from naupliar setae (Thecostraca: Cirripedia, Ascothoracida and Facetotecta), Zool. Anz., 2003, vol. 242, pp. 1-20.

57. Rybakov, A.V., Korn, O.M., Høeg, J.T., and Waloszek, D., Larval development in Peltogasterella studied by scanning electron microscopy (Crustacea: Cirripedia: Rhizocephala), Zool. Anz., 2002, vol. 241, pp. 199-221.

58. Trédez F., Rabet N., Bellec L., Audebert F. Synchronism of naupliar development of Sacculina carcini Thompson, 1836 (Pancrustacea, Rhizocephala) re- vealed by precise monitoring, Helgol. Mar. Res., 2016, vol. 70 , no. 26 , pp. $1-11$.

59. Tu, T.-H., Chan, B.K.K., and Jeng, M.-S., Larval development and sex ratio variation of Polyascus plana (Cirripedia: Rhizocephala), a parasite of the crab Grapsus albolineatus, in Taiwan, Bull. Mar. Sci., 2009, vol. 84 , no. 3 , pp. $331-349$.

60. Walker, G., The cypris larvae of Sacculina carcini Thompson (Crustacea: Cirripedia: Rhizocephala), J. Exp. Mar. Biol. Ecol., 1985, vol. 93, pp. 131-145.

61. Walker, G., Observations on the larval development of Sacculina carcini (Crustacea: Cirripedia: Rhizocephala), J. Mar. Biol. Assoc. U. K., 1988, vol. 68, no. 3, pp. 377-390.

62. Walker, G., The cypris larvae of the rhizocephalan barnacle Heterosaccus lunatus with particular reference to antennular morphology, Acta Zool., 1999, vol. 80, pp. 209-217.

63. Walker, G., Introduction to the Rhizocephala (Crustacea: Cirripedia), J. Morphol., 2001, vol. 249, pp. 1-8.

64. Walker, G. and Clare, A.S., The effect of salinity on the development of Loxothylacus panopaei larvae (Crustacea: Cirripedia: Rhizocephala), Estuaries, 1994, vol. 17, pp. 276-282.

65. Walker, G. and Lester, R.J.G., Effects of salinity on development of larvae of Heterosaccus lunatus, J. Crustacean Biol., 1998, vol. 18, no. 4, pp. 650-655.

66. Walossek, D., Høeg, J.T., and Shirley, T.C., Larval development of the rhizocephalan cirripede Briarosaccus tenellus (Maxillopoda: Thecostraca) reared in the laboratory: A scanning electron microscopy study, Hydrobiologia, 1996, vol. 328, pp. 9-47.

67. Yoshida, R., Hirose, M., and Hirose, E., A new peltogastrid rhizocephalan parasitising a hermit crab from the Japanese coast: A second species of Dipterosaccus Van Kampen \& Boschma, 1925 (Crustacea: Cirripedia), Syst. Parasitol., 2013, vol. 84, pp. 137-147.

68. Yoshida, R., Hirose, M., and Hirose, E., Peltogasterella sensuru n. sp. (Crustacea: Cirripedia: Rhizocephala) from off Okinawa Island (Ryukyu Archipelago, Japan) with remarks on its single brood externae, Syst. Parasitol., 2015, vol. 92, pp. 31-44.

69. Yoshida, R., Osawa, M., Hirose, M., and Hirose, E., A new genus and two new species of Peltogastridae (Crustacea: Cirripedia: Rhizocephala) parasitizing hermit crabs from Okinawa Island (Ryukyu Archipelago, Japan), and their DNA-barcodes, Zool. Sci., 2011, vol. 28 , pp. $853-862$.

70. Glenner, H., Thomsen, P.F., Rybakov, A.V., et al., The phylogeny of rhizocephalan parasites of the genus Heterosaccus using molecular and larval data (Cirripedia: Rhizocephala: Sacculinidae), Isr. J. Ecol. Evol., 2008, vol. 54, pp. 223-238.

Translated by T. Koznova 